\title{
Frequent seizures and polytherapy can impair quality of life in persons with epilepsy
}

\author{
Sanjeev V. Thomas, Samuel Koshy*, C. R. Sudhakaran Nair*, Sankara P. Sarma \\ Department of Neurology, Sree Chitra Tirunal Institute for Medical Sciences and Technology, *College of Pharmaceutical Sciences, Medical \\ College, Trivandrum, India
}

Context: Careful evaluation of pharmacotherapy, seizure control and quality of life (QOL) are helpful in improving epilepsy care but such data are relatively meager from developing countries. Aims: To audit pharmacotherapy, seizure control and QOL in persons with epilepsy and to identify factors associated with impaired QOL. Settings and Design and Materials and Methods: The study was carried out using a cross-sectional design in the setting of a tertiary care epilepsy center in India. Persons with epilepsy with >12 months follow-up at this Center and aged $>16$ years were eligible for enrollment. Persons with other disabilities or pregnancy were excluded. Subjects were interviewed with a standard questionnaire and an adapted version of Quality of Life in Epilepsy - 31 (QOLIE-31). Data pertaining to treatment at the time of referral to this center was extracted from medical records. Statistical Analysis Used: Chi-square test, analysis of variance and multiple regression analysis were carried out for statistical significance. Results: One hundred and twelve patients with epilepsy (59 males, mean age $31.2 \pm 10.7$ years) were included. Forty-seven (42\%) persons had Generalized Epilepsy (GE) and 65 persons (58\%) had Localization-Related Epilepsy (LRE). At entry 24 persons (21.4\%) were not on treatment and 59 persons (64.8\%) had frequent seizures. At last follow-up 64 persons (57.1\%) were seizure-free, 83 persons $(74.1 \%)$ were on monotherapy and 29 were $(25.9 \%)$ on polytherapy. Cost of drug at entry was INR 2276 (monotherapy) and INR 3629 (polytherapy) (45 INR = 1 USD). At the time of last follow-up, it was 1898 and 4929 respectively. QOLIE-31 Total Score (TQOL) ranged from 22.6 to 94.4 (mean $68.0 \pm 15.8$ ). Multiple regression analysis showed significant correlation between low TQOL score and polytherapy $(P=0.002)$ and occurrence of one or more seizures per month $(P=0.001)$. Conclusions: Frequent seizures and polytherapy are associated with lower QOL in persons with epilepsy.

Key Words: Quality of life, cost, pharmacotherapy, seizure control

\section{Introduction}

World Health Organization and the International League against Epilepsy have estimated that 34 million out of 40 million people with epilepsy in the world live in developing countries and nearly $80 \%$ of them are not on treatment. The paucity of medical infrastructure, poor affordability, and certain social or cultural beliefs interfere with optimal care for epilepsy in these countries. The benefit of treatment is commonly measured from a caregiver's perspective that often includes seizure frequency, occurrence of adverse effects and other laboratory measures. The impact of epilepsy on the life of the patient, particularly in the psychosocial realm is not adequately represented in such estimates. Recently, Quality of life (QOL) measures have been included to supplement other outcome measures with the patient's perspective also. QOL evaluation in epilepsy passed through several phases before it reached the current concepts. ${ }^{[1]}$ Several tools have been developed to estimate QOL in epilepsy in different settings such as drug trials, epilepsy surgery programs and for general purposes such as QOLIE-31, ${ }^{[2]}$ Epilepsy Surgery Inventory (ESI$55)^{[3]}$ and Short form- 36(SF-36 $)^{[4]}$ respectively. The treatment of epilepsy vis-à-vis QOL has not been adequately audited in developing countries. The main objective of this study was to audit the pharmacotherapy, seizure frequency and QOL in the setting of a referral hospital in a developing country. The other objective of this study was to ascertain any association between QOL and demographic characteristics (such as sex, age, occupation), disease characteristics (such as type of epilepsy, duration, seizure frequency) and pharmacotherapy characteristics (monotherapy vs. polytherapy, type of Anti-Epileptic Drug (AED) used and occurrence of adverse drug reactions $(\mathrm{ADR}))$. 


\section{Materials and Methods}

This study was carried out at the R. Madhavan Nair Center for Comprehensive Epilepsy Care in Sree Chitra Tirunal Institute, Trivandrum, Kerala, India. We accept patients only on referral from peripheral centers (any medical practitioner or clinic). Approximately 800 to 900 persons with epilepsy are enrolled in this center every year and about 60 persons with medically refractory epilepsy are operated every year with a $65-80 \%$ success rate. Some 80 to 100 patients with epilepsy are reviewed every week in the two clinics attached to this center. Consecutive outpatients attending the epilepsy clinics of this Center between August and October 2003 were considered for possible inclusion in this study. Only those persons with definite diagnosis of epilepsy, age more than 16 years and follow-up in this Center for 12 months or more were eligible for inclusion. Terminology according to ILAE classification of seizures and epileptic syndromes ${ }^{[5]}$ was followed. Pregnant women, persons who are not conversant with Malayalam language and persons with significant disabilities such as mental retardation, motor disability (cerebral palsy, hemiparesis, ataxia, etc) language disability, visual or hearing impairment, psychosis or other medical or surgical infirmity were excluded. Persons who were otherwise eligible but not willing to participate in the study due to lack of time or disinclination were also excluded. The study was carried out with the permission of the Institute. Informed consent was obtained from all persons. Details of clinical condition, seizure frequency and antiepileptic drug (AED) status at the time of entry to this Center, were extracted from the medical records. At the time of last followup i.e. when the patients were enrolled and data were compiled, all subjects were administered a structured questionnaire regarding current seizure frequency, compliance with drug therapy, and a checklist for possible ADR. QOLIE-31 questionnaire was also administered at the same visit. Seizure burden was scored according to Engel system ${ }^{[6]}$ that scores seizure frequency and disability on a quasi-logarithmic scale ranging from 0-12. Scores less than 5 indicate no seizures or non-disabling seizures (aura or brief partial seizures without impairment of consciousness or loss of muscular tone) only. Score 5 denotes 1 to 3 seizures per year; score 6 indicates 4-11 seizures per year. Seizure frequency of 1 per month and above is scored 7-12. Absence seizures and myoclonic seizures were not counted for the purpose of seizure frequency. Seizure freedom was defined as absence of disabling seizures for more than 12 months continuously.

We have recorded the dosage of AEDs as a ratio of Prescribed Daily Dosage to Daily Defined Dosage (PDD/DDD). PDD refers to the total dose per day prescribed for a given AED. WHO has defined the daily-defined dose of a drug (DDD) as the assumed average maintenance dose per day used for its main indication in a reference

\begin{tabular}{|c|c|c|}
\hline \multicolumn{3}{|c|}{$\begin{array}{c}\text { Table 1: Daily defined dosage of anti-epileptic drugs modified } \\
\text { according to body weight }\end{array}$} \\
\hline AED & $\mathrm{DDD}^{\star \star}(\mathrm{mg})$ & Modified DDD** $(\mathrm{mg})$ \\
\hline PB & 100 & 75 \\
\hline $\mathrm{CBZ}$ & 1000 & 800 \\
\hline VPA & 1500 & 1000 \\
\hline $\mathrm{PHT}$ & 300 & 200 \\
\hline CLB & 20 & 15 \\
\hline CZP & 8 & 6 \\
\hline
\end{tabular}

AED, anti-epileptic drug; *DDD, daily defined dose recommended for reference person of weight $70 \mathrm{~kg}$; ${ }^{* \star}$ Modified DDD, modified daily defined dose for reference Indian of weight $50 \mathrm{~kg}$, adjusted to nearest prescribable dosage. person of 70 kilograms body weight. The reference weight for a man and a woman in the Indian population, according to the Indian Council of Medical research (ICMR) ${ }^{[7]}$ is $55 \mathrm{~kg}$ and $45 \mathrm{~kg}$ respectively. For the purpose of this study, we have taken the reference weight for a person as $50 \mathrm{~kg}$ and modified the DDD as given in Table 1 . We used the market price of AEDs to estimate cost. QOL was measured using adapted translation of QOLIE-31 $1^{[2]}$ that was in use in this Institution for several years. The original English version was translated into the local (Malayalam) language and accuracy was ascertained by back translation. We had adapted the QOLIE-31 to suit the local socio-cultural milieu by modifying some questions, for e.g. ability to drive was replaced by ability to travel independently. QOLIE-31 has one visual analogue scale of overall quality of life and 30 questions pertaining to diverse aspects of QOL. Each aspect, the number of questions under that aspect and the range score for that aspect were as follows: Seizure worry (5, 0-8), Overall quality of life (2, 0-14), Emotional well-being (5, 0-15), Energy or Fatigue (4, 0-12), Cognitive performance $(6,0-27)$, Medication effects $(3,0-3)$ and Social function (5, 0-21), Total score (30, 0-100). A lower score indicates poor quality of life and higher score indicates better quality of life. Chi-square test, ANOVA and multiple regression analysis were employed on SPSS package to ascertain statistical significance. $P$ values less than 0.05 were taken as statistically significant.

\section{Results}

We studied 112 patients (59 males and 53 females) with epilepsy, mean age was $31.2 \pm 10.7$ years (range $17-60$ years). Mean age of onset of epilepsy was $17.5 \pm 9.9$ years and mean age of initiation of AED therapy was $23.1 \pm 10.0$ years. The epileptic syndrome was generalized epilepsy (GE) in 47 persons and localization-related epilepsy (LRE) in 65 persons. There were 20 students, 48 employed persons and 41 unemployed persons. Employment status was not ascertained for three persons.

At the time of entry to this Institute, 24 persons were not taking any AEDs for reasons including lack of therapeutic effectiveness, use of traditional medicines, adverse effects of medicines, recent onset of epilepsy, non-disabling nature of seizures and prohibitive cost of drugs. Treatment delay for those who were on AEDs was 3.0 43.0 years (range 0.08-12 years). The delay in treatment was attributed to the use of traditional medicines, non-disabling nature of seizures and different diagnosis. Details of pharmacotherapy at last follow-up in comparison to that at the time of entry is given in Table 2. The drugs prescribed for GE were valproate (VPA) $36(76.6 \%)$, phenytoin (PHT) $6(12.8 \%)$, phenobarbitone (PB) $3(6.4 \%)$, carbamazepine (CBZ) $3(6.4 \%)$ and clonazepam (CZP) 2(4.3\%), while those for LRE were CBZ 45(69.23\%), clobazam (CLB) 15(23.1\%), PHT 14(21.5\%), PB 10(15.4\%), VPA $4(6.2 \%)$ and CZP 1(1.5\%). Combinations between primary drugs (CBZ, VPA, PHT and PB) decreased while combination of primary drug (mostly CBZ) and CLB increased (Table 2) at the time of last follow-up when compared to entry to the referral center. The mean PDD/DDD ratios of most AEDs at the time of entry to the Center were lower than at 


\begin{tabular}{|c|c|c|}
\hline & $\begin{array}{l}\text { At the time of } \\
\text { entry } N(\%)\end{array}$ & $\begin{array}{l}\text { At the time of last } \\
\text { follow-up N (\%) }\end{array}$ \\
\hline Not on AEDs & $24(21.4)$ & 0 \\
\hline Monotherapy & $45(45.9)$ & $83(74.1)$ \\
\hline Polytherapy & $29(29.6)$ & $29(25.9)$ \\
\hline \multicolumn{3}{|l|}{ AED } \\
\hline Phenobarbitone (PB) & $27(27.5)$ & $13(11.6)$ \\
\hline Mean PDD/DDD & 1.2 & 1.4 \\
\hline Phenytoin (PHT) & $23(23.5)$ & $20(17.9)$ \\
\hline Mean PDD/DDD & 1.1 & 1.4 \\
\hline Carbamazepine (CBZ) & $37(37.8)$ & $48(42.9)$ \\
\hline Mean PDD/DDD & 0.7 & 1.0 \\
\hline Valproate (VPA) & $18(18.4)$ & $40(35.7)$ \\
\hline Mean PDD/DDD & 0.7 & 0.7 \\
\hline Clobazam (CLB) & $4(4.1)$ & 159 (3.4) \\
\hline Mean PDD/DDD & 1.0 & 1.2 \\
\hline Clonazepam & $2(2.0)$ & $3(2.7)$ \\
\hline Mean PDD/DDD & 0.4 & 0.3 \\
\hline \multicolumn{3}{|l|}{ AED Combinations } \\
\hline $\mathrm{PB}+\mathrm{PHT}$ & $4(5.4)$ & $4(3.6)$ \\
\hline$P B+C B Z$ & $3(4.1)$ & $3(2.7)$ \\
\hline $\mathrm{PHT}+\mathrm{CBZ}$ & $3(4.1)$ & $2(1.8)$ \\
\hline $\mathrm{CBZ}+\mathrm{VPA}$ & $394.1)$ & $2(1.8)$ \\
\hline $\mathrm{CBZ}+\mathrm{CLB}$ & $2(2.7)$ & $14(12.5)$ \\
\hline \multicolumn{3}{|c|}{ Seizure frequency (Engel Score) } \\
\hline unknown & 21 & 0 \\
\hline$<5$ & 0 & $64(57.1)$ \\
\hline $5-6$ & $32(35.2)$ & $40(35.7)$ \\
\hline$>6$ & $59(64.8)$ & $8(7.1)$ \\
\hline
\end{tabular}

AED, Anti-Epileptic Drug; DDD, modified Daily Defined Dose; PDD, Prescribed Daily Dose

the time of last follow-up (Table 2). On last follow-up, ADRs were recorded in 19 (16.9\%) persons. They included drowsiness and memory impairment in three persons each, headache, gum hypertrophy, and weight gain in two each, and sedation, diplopia, tremor, dry skin, nausea, enuresis and eosinophilia in one patient each.

At the time of referral to this Center, none were seizure-free (Engel score < 5) and at last follow-up in this Center 64 persons were seizure-free (Table 2 ). Seizure control was significantly better $(P=0.02)$ for persons with GE $(68.1 \%)$ when compared to persons with LRE (49.2\%).

Annual cost of AEDs for a person on monotherapy was INR 2276 at the time of entry to this Center. (Indian rupees, INR 45 = US Dollars, USD 1.) The annual cost of AEDs declined to INR 1898 at last follow-up at this Center whereas the annual cost for polytherapy increased from INR 3621 to INR 4929 per person. The annual cost of AEDs per person for monotherapy and polytherapy in this study was $8.8 \%$ and $22.8 \%$ respectively of the per capita Gross National Income (GNI). The per capita GNI for an Indian in 2002 was USD 480). ${ }^{[8]}$

QOLIE-31 scale total score (TQOL) ranged from 22.6 to 94.4 (mean $68.0 \pm 15.8$ ). The interquartile range was 21.8. Mean scores on QOLIE-31 subscales were seizure worry (5.5 \pm 2.2$)$, emotional well-being $(8.9 \pm 2.8)$, energy/fatigue

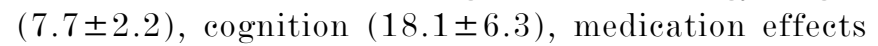
$(1.8 \pm 0.9)$, social function $(16.4 \pm 4.3)$. All subcomponents

\begin{tabular}{|c|c|c|c|c|}
\hline Variable & Characteristic & $\mathbf{N}$ & $\begin{array}{c}\text { Total QOL } \\
\text { score Mean (SD) }\end{array}$ & $(P)^{*}$ \\
\hline Sex & $\begin{array}{c}\text { Male } \\
\text { Female }\end{array}$ & $\begin{array}{l}59 \\
53\end{array}$ & $\begin{array}{l}67.7(16.3 \\
68.5(15.5)\end{array}$ & 0.78 \\
\hline Age (years) & $\begin{array}{c}<20 \\
20-29 \\
30-39 \\
>40\end{array}$ & $\begin{array}{l}13 \\
47 \\
28 \\
24\end{array}$ & $\begin{array}{l}66.3(18.9) \\
69.0(14.6) \\
66.0(18.9) \\
69.5(12.9)\end{array}$ & 0.81 \\
\hline Occupation & $\begin{array}{c}\text { Student } \\
\text { Employed } \\
\text { Unemployed } \\
\text { Unascertained }\end{array}$ & $\begin{array}{l}20 \\
48 \\
41 \\
03\end{array}$ & $\begin{array}{l}74.3(11.2) \\
67.9(14.2) \\
67.2(17.6)\end{array}$ & 0.193 \\
\hline Epilepsy type & $\begin{array}{l}\text { LRE } \\
\text { GE }\end{array}$ & $\begin{array}{l}47 \\
65\end{array}$ & $\begin{array}{l}65.4(18.1) \\
71.4(11.3)\end{array}$ & 0.035 \\
\hline $\begin{array}{l}\text { Duration of } \\
\text { epilepsy (years) }\end{array}$ & $\begin{array}{c}<10 \\
10-19 \\
20-29 \\
>30\end{array}$ & $\begin{array}{c}46 \\
38 \\
20 \\
8\end{array}$ & $\begin{array}{l}70.3(14.2) \\
67.3(17.6) \\
67.5(16.0) \\
60.7(16.5)\end{array}$ & 0.328 \\
\hline $\begin{array}{l}\text { Seizure frequency } \\
\text { Engle Score }\end{array}$ & $\begin{array}{l}<5 \\
5-6 \\
>6\end{array}$ & $\begin{array}{l}64 \\
40 \\
08\end{array}$ & $\begin{array}{l}71.5(14.1) \\
66.8(14.1) \\
50.6(21.8)\end{array}$ & 0.001 \\
\hline Drug therapy & $\begin{array}{l}\text { Monotherapy } \\
\text { Polytherapy }\end{array}$ & $\begin{array}{l}83 \\
29\end{array}$ & $\begin{array}{l}70.7(14.9) \\
60.2(16.0)\end{array}$ & 0.002 \\
\hline $\begin{array}{l}\text { Anti-epileptic } \\
\text { drugs }\end{array}$ & $\begin{array}{l}\text { CBZ } \\
\text { PB } \\
\text { PHT } \\
\text { VPA }\end{array}$ & $\begin{array}{l}48 \\
13 \\
20 \\
40\end{array}$ & $\begin{array}{l}68.2(20.0) \\
66.3(13.3) \\
69.9(14.2) \\
73.5(10.8)\end{array}$ & $\begin{array}{l}0.29 \\
0.45 \\
0.84 \\
0.13\end{array}$ \\
\hline $\begin{array}{l}\text { Adverse drug } \\
\text { reactions }\end{array}$ & $\begin{array}{c}\text { No ADR } \\
\text { ADR present }\end{array}$ & $\begin{array}{l}93 \\
19\end{array}$ & $\begin{array}{l}67.8(16.3) \\
67.3(13.9)\end{array}$ & 0.89 \\
\hline
\end{tabular}

*Statistical significance on the basis of Analysis of Variance (ANOVA) ADR = Adverse Drug Reaction; CBZ = Carbamazepine; GE = Generalized Epilepsy LRE = Localization-Related Epilepsy; PB = Phenobarbitone PHT = Phenytoin; $\mathrm{QOL}=$ Quality Of Life SD = Standard Deviation; VPA = Valproic acid.

co-varied with the total score. Mean TQOL scores for demographic characteristics, type of epilepsy, seizure frequency and AED use are given in Table 3. On analysis of variance, there was no significant association between TQOL and gender, age group and occupation of patients. Duration of epilepsy or any specific AEDs did not have any significant association with TQOL. Mean TQOL for LRE $(65.4 \pm 18.1)$ was significantly lower (degree of freedom 110, 95\% Confidence interval -12 . to $-0.45, P=0.035)$ than that for GE $(71.4 \pm 11.3)$. Patients who were on monotherapy had higher TQOL $(70.8 \pm 14.9)$ when compared to those who were on polytherapy $(60.2 \pm 16.0)$ which was statistically significant (degree of freedom 110, 95\% Confidence Interval 4.07$17.07, P=0.002)$. On analysis of variance, mean TQOL had a statistically significant association with seizure frequency (Table 3). A stepwise multiple regression analysis was carried out with the model including these factors as independent variables and TQOL as dependent variable. The model had an adjusted $\mathrm{R}^{2}=0.147$. The results revealed a statistically significant independent association between lower TQOL and polytherapy (standardized beta -0.196 , $P=0.041$ ) and Engel score of seizure frequency $>6$ (standardized beta $-0.281, P=0.003)$. 


\section{Discussion}

The salient observations in this study were that at the time of entry to the study, the treatment gap was around $21 \%$, more patients were experiencing frequent seizures despite use of polytherapy and overall cost of treatment was high. At the time of last follow-up in this center, fewer patients were on polytherapy, seizure control was better and overall cost of treatment was lower. Frequent seizures and use of polytherapy were independently associated with lower total score on QOLIE31 scale of QOL.

Limited resources and higher treatment gaps characterize epilepsy care in developing countries. ${ }^{[9]}$ In this study, we have focused on pharmacotherapy profile, seizure control and QOL for a cohort of persons with epilepsy attending a tertiary referral epilepsy center in a developing country. This particular setting had enabled us to examine the pharmacotherapy of epilepsy in this advanced care center in comparison to the peripheral centers from where the patients were referred to us. The absence of QOLIE-31 evaluation at the time of entry to the center and the absence of formal psychological profiling are the two limitations of this study. The AED profile at the time of entry to this referral center for epilepsy reflects the prescribing practices prevailing in the peripheral centers. The prevailing scenario when patients are referred from peripheral centers is characterized by usage of relatively low dosages (PDD/DDD <1) of AEDs, polytherapy and high seizure frequency. It appeared that in peripheral centers polytherapy was adopted more readily rather than prescribing higher doses of monotherapy, when confronted with poor control of seizures.

Nearly a quarter of persons were not on treatment at the time of referral (entry to this Center). Treatment gap in developing countries in general is high, to the tune of $80 \% .^{[9]}$ The treatment gap in this study was much lower (21.4\%) but was comparable to that observed in a community study (38\%) carried out in same state. ${ }^{[10]}$ Higher educational and general health standards prevailing in the Kerala State in India could possibly be one of the reasons for the relatively lower treatment gap found in this study as well as the previous study. Reasons for the treatment gap for persons referred to tertiary epilepsy centers (lack of therapeutic effectiveness, use of traditional medicines, adverse effects of medicines, recent onset of epilepsy, non-disabling nature of seizures and prohibitive cost of drugs) are different from those observed in epidemiological studies (lack of prioritization, poor infrastructure, cost and supply of AEDs and different perceptions of the disease in different countries). ${ }^{[9]}$

In this study we observed that monotherapy is probably underutilized in the peripheral centers. Similar observations were made in an earlier study also. ${ }^{[11]}$ In the present study several persons were shifted to sodium valproate therapy after a diagnosis of GE was confirmed. Such practices have been documented elsewhere also. ${ }^{[12,13]}$ WHO had recommended PB as the first-line drug, ${ }^{[14]}$ a policy that appears to be largely influenced by economic reasons. PB is widely used in India. Two earlier studies from India ${ }^{[15,16]}$ have shown that epilepsy can be successfully treated with PB or PHT with no excess adverse effects. PB may have a limited role in LRE particularly when seizures have become medically intractable. The proportion of patients on polytherapy had decreased at the time of the last follow-up. The pattern of polytherapy practiced in this referral center (combination of CBZ and CLB) differed from that followed in peripheral centers (combinations between CBZ, VPA, PHT, and PB). This shift in polytherapy practice probably reflects the recent trend for rational polytherapy. ${ }^{[17]}$ The frequency of polytherapy in this study is comparable with other referral centers in India. ${ }^{[18]}$ Polytherapy is generally reserved for refractory seizures largely due to LRE. ADR were observed only in $16.9 \%$ of the persons at last follow-up, which was comparable with earlier observations. ${ }^{[1]}$

The cost of drugs is an important factor in developing countries, since it constitutes $57 \%$ of the total direct cost. ${ }^{[19]}$ The annual cost of AEDs for monotherapy, in this study, was about $9 \%$ of GNI per capita and increased two and a half times if a person was on polytherapy. The price of the drugs influences the prescription pattern in India to a large extent because such expenditure is borne by the patient and his family in the majority of instances. One of the reasons for treatment gap in this study was the prohibitive cost of drugs.

The quality of life evaluation is a relatively new measure to evaluate the outcome of treatment for epilepsy. QOL is influenced by biological factors as well as cultural, social and religious beliefs and values. We evaluated QOL with QOLIE-31, an instrument that covers several domains with reference to a specific time period. This is the first report on QOL from India. The QOLIE-31 was adapted for the Indian social milieu. In this study the TQOL ranged from 22.6 to 94.4 but the mean was 68.0 (SD 15.8). In the earlier studies several factors have been identified to correlate significantly with QOL; seizure frequency, ${ }^{[20-22]}$ presence of adverse effects, ${ }^{[23]}$ female gender, ${ }^{[20]}$ low educational status and psychosocial factors are some of them. ${ }^{[20,24]}$ In our series only three factors LRE, seizure frequency of one or more per month, and polytherapy - were associated with lower TQOL on ANOVA. Use of PB was associated with marginally lower cognition score but did not have statistical significance. Multiple regressions with these factors included in the model, identified frequent seizures and polytherapy to be independently associated with lower TQOL scores. In contrast to some of the earlier reports, gender, educational status and presence of ADR did not have any significant association with TQOL in this study. This protocol did not allow for any correlation between TQOL and psychological factors, since such data were not collected. Our observation that frequent seizures and polytherapy have significant association with QOL empha- 
sizes the pivotal role of these two aspects in epilepsy care. QOL estimate is a useful outcome measure to assess epilepsy care from a patient's perspective. It is relatively easy to give out simple self-administered QOL instruments like QOLIE31 even in busy epilepsy clinics in developing countries. The management of a person with epilepsy should focus on better control of seizures with appropriate use of AEDs, preferably monotherapy, which would improve quality of life.

\section{References}

1. Hermann BP. The evolution of health related quality of life assessment in epilepsy. Qual Life Res 1995;4:87-100.

2. Cramer JA, Perrine K, Devinsky O, Bryant-Comstock L, Meador K, Hermann B. Development and cross cultural translations of a 31-item quality of life in epilepsy inventory. Epilepsia 1998;39:81-8.

3. Vickrey BG, Hays RD, Graber J, Rausch R, Engel J Jr, Brook RH. A health related quality of life instrument for patients evaluated for epilepsy surgery. Med Care 1992;30:299-319.

4. Ware JE Jr, Sherbourne CD. The MOS 36 - item short form health survey (SF-36). Conceptual framework and item selection. Med Care $1992 ; 30: 473-83$

5. Commission on Classification and Terminology of the International League Against Epilepsy. Proposal for revised classification of epilepsies and epileptic syndromes. Epilepsia 1989;30:389-99.

6. Engel J Jr, Ness V, Rasmussen, Ojemann LM. Outcome with respect to epileptic seizures. In: Surgical treatment of the epilepsies (Ed Engel J Jr). New York: Raven Press; 1993. p. 609-22.

7. Antia FP. Clinical dieteties and nutrition. $3^{\text {rd }}$ Ed. New York: Oxford University Press; 1989.

8. World development report. New York: Oxford University Press; 2004. p. 252.

9. Scott RA, Lhatoo SD, Sander JWAS. The treatment of epilepsy in developing countries: Where do we go from here? Bulletin of the World Health Organization 2001;79:344-51.

10. Radhakrishnan K, Pandian JP, Santhoshkumar T, Thomas SV, Deetha TP, Sarma PS, et al. Prevalence, knowledge, attitude and practice of epilepsy in
Kerala and India. Epilepsia 2000;41:1027-35.

11. Radhakrishnan K, Nayak PS, Kumar SP, Sarma PS. Profile of antiepileptic pharmacotherapy in a tertiary referral centre in South India: A pharmacoepidemiologic and pharmacoeconomic study. Epilepsia 1999;40:179-85

12. Kleveland G, Engelsen BA. Juvenile myoclonic epilepsy: Clinical characteristies, treatment and prognosis in a Norwegian population of patients. Seizure $1998 ; 7: 31-8$.

13. Atkali D, Sozuer D, Atay T, Baybas S, Arpaci B. Misdiagnosis and treatment in juvenile myoclonic epilepsy. Seizure 1998;7:63-6.

14. World Health Organization. Initiative of support to people with epilepsy. Geneva: World Health Organization; 1990.

15. Mani KS, Rangan G, Srinivas HV, Srindharan VS, Subbakrishna DK. Epilepsy control with Phenobarbital or phenytoin in rural South India: The Yelandur study. Lancet 2001;357:1316-20.

16. Pal DK, Das T, Chaudhury G, Johnson AL, Neville BG. Randomised controlled trial to assess acceptability of Phenobarbital for childhood epilepsy in rural India. Lancet 1998;351:19-23.

17. Perucca E. Current trends in antiepilepstic drug therapy. Epilepsia $2003 ; 44: 41-7$.

18. Thomas SV, Sarma PS, Alexander M, Pandit L, Shekhar L, Trivedi C, et al. Epilepsy care in six Indian cities: A multistudy on management and service. J Neurol Sci 2001;188:73-7.

19. Thomas SV, Sarma PS, Alexander M, Pandit L, Shekhar L, Trivedi C, et al. Economic burden of epilepsy in India. Epilepsia 2001;42:1052-60.

20. Shakarishvilli DM. Influence of clinical, demographic and socioeconomic variables on QOL in patients with epilepsy: Findings from Georgian study. J Neurol Neurosurg Psychiatry 2003;74:570-73.

21. Leidy NK, Elixhauser A, Vickrtey B, Means E, William MK. Seizure frequency and the health related quality of life of adults with epilepsy. Neurology $1999 ; 53: 162-6$

22. Haut BV, Gagnon D, Soutre E, Reid S, Remy C, Baker G, et al. Relationship between seizure frequency and costs and quality of life of outpatients with partial epilepsy in France, Germany and the United Kingdom. Epilepsia 1997;38:1221-6.

23. Baker G, Jacoby A, Buck D, Stalgis C, Monnet D. Quality of life of people with epilepsy: A European study. Epilepsia 1997;38:353-62.

24. Choi-Kwon S, Chung C, Kim H, Lee S, Yoon S, Kho H, et al. Factors affecting the quality of life in patients with epilepsy in Seol, South Korea. Acta Neurol Scand $2003 ; 108: 428-34$

Accepted on 11.12.2004 